\title{
ЛИНГВОКРЕАТИВНОЕ ВЗАИМОДЕЙСТВИЕ ЗНАКОВ РАЗНЫХ СЕМИОТИЧЕСКИХ СИСТЕМ В ТЕКСТАХ СОВРЕМЕННОГО НЕМЕЦКОГО ПОЛИТИЧЕСКОГО ПЛАКАТА
}

\section{LINGUOCREATIVE INTERACTION OF SIGNS BELONGING TO DIFFERENT SEMIOTIC SYSTEMS IN THE TEXTS OF MODERN GERMAN POLITICAL POSTER}

A. Filatova

Summary: The article is devoted to the specifics of interaction of language signs with the signs of other semiotic systems, which can be considered as a signal of the manifestation of linguocreativity in modern German political posters. A political poster is regarded as a kind of polycode text. The authors describe the composition of political poster, analyse different types of correlation between verbal and iconic components, determine their linguocreative potential and attempt to define, in which part of the political poster linguocreativity emerges.

Keywords: creolized text, polycode text, political poster, political discourse, linguocreativity.

\author{
Филатова Алёна Григорьевна \\ Аспирант, РГПУ им. А.И. Гериена (Санкт-Петербург) \\ alyonafilatowa@gmail.com
}

Аннотация: Статья посвящена особенностям взаимодействия языковых элементов со знаками других семиотических систем как сигнала проявления лингвокреативности в современных немецких политических плакатах, принадлежащих к поликодовому типу текста. В статье определяется композиция плаката, анализируются различные виды связи между языковыми и иконическим текстовыми компонентами, выявляется их лингвокреативный потенциал, а также предпринимается попытка определить, в какой из частей плаката зарождается лингвокреативность.

Ключевые слова: креолизованный текст, поликодовый текст, политический плакат, политический дискурс, лингвокреативность.

и изучение функциональных свойств лингвокреативных элементов, зависящих от их позиции в структуре текста.

Материалом исследования послужили 200 плакатов современных немецких политических партий за период с 2010 по 2021 год: Альтернатива для Германии (АдГ/AfD), Христианско-демократический союз Германии (ХДС) (DU), Свободная демократическая партия Германии (СвДП/FDP), Союз 90/Зелёные (Bündnis 90/Die Grünen), Левая партия (die Linke) и Социал-демократическая партия Германии (СДПГ/SPD). Исследование проводилось на методической основе контекстуально-интерпретационного анализа текстов плаката и последующего теоретического обобщения полученных результатов непосредственного наблюдения над текстовым материалом.

Для изучения феномена лингвокреативности важно определить, к какому классу текстов относится политический плакат. Политический плакат представляет собой в формальном плане особый тип текста со структурным сочетанием вербальных и визуальных элементов, что позволяет отнести его к поликодовым текстам. Подобные тексты с гетерогенной структурой продолжают оставаться сегодня в фокусе внимания многих учёных, однако до сих пор они не получили единого терминологического обозначения. В науку вошли такие их определения как креолизованный текст $[1 ; 2 ; 15]$, поликодовый текст [5; 
13; 14], изоверб [9], изовербальный комплекс [3], видеовербальный текст [7; 11], полимодальный текст [10], семиотически осложнённый текст [12]. Наиболее широкое распространение в научной коммуникации получили понятия креолизованного и поликодового текста.

Само понятие «креолизованный текст» в своё время ввели в научный обиход Ю.А. Сорокин и Е.Ф. Тарасов, понимая под ним «тексты, фактура которых состоит из двух негомогенных частей: вербальной (языковой/речевой) и невербальной (принадлежащей к другим знаковым системам, нежели естественный язык)» [15, с. 180]. В определении Е.Е. Анисимовой, также активно занимающейся изучением названного типа текстов, подчёркивается имманентная связь между (отдельными) частями креолизованного текста. По мнению исследователя, креолизованный текст - это «особый лингвовизуальный феномен, текст, в котором вербальный и изобразительный компоненты образуют одно визуальное, структурное, смысловое и функциональное целое, обеспечивающее его комплексное прагматическое воздействие на адресата» [1, c. 73]. Поликодовые тексты определяются более широко - как «тексты, построенные на соединении в едином графическом пространстве семиотически гетерогенных составляющих - вербального текста в устной или письменной форме, изображения, а также знаков иной природы» [13, с. 117]. А.А. Бернацкая предлагает разграничивать понятия креолизованного и поликодового текста следующим образом: поликодовость используется для обозначения родового понятия гетерогенных, синкретических текстов, а креолизация затрагивает степень участия знаков разных семиотических систем в создании текста [4, с. 106].

Основное прагматическое назначение политического плаката как средства политической визуальной коммуникации, использующего элементы разных знаковых систем, заключается в воздействии на массового гетерогенного адресата с целью формирования у него определённого мнения, выгодного адресанту. Это, в свою очередь, определяет, кроме вышеотмеченного признака, две ключевые характеристики построения рассматриваемого типа текста: во-первых, доступную форму трансляции информации, а, во-вторых, ограниченность текстового пространства для передачи авторской мысли, что требует наличия у каждого структурно-семантического элемента плаката высокого персуазивного потенциала, включающего не только и не столько аргументативно-логический, сколько эмоционально-экспрессивный виды воздействия на читателя.

Как и всякому другому тексту, политическому плакату свойственна определённая композиция, т. е. группировка, последовательность и сочетание тематико-смысловых частей в его внутренней структуре. Композицию любого современного политического плаката составляют две части: информативная и персуазивно-апеллятивная. В информативной части плаката заключены данные о политической партии и кандидатах, о дате и месте прохождения выборов и т.д. Персуазивно-апеллятивная часть содержит призыв адресата к определённому действию: действию ментального характера (т.е. изменению мировоззрения, смене идеологии) и/или конкретному действию (проголосовать за партию, поддержать кандидата).

Проиллюстрируем сказанное на примере предвыборного плаката партии ХДС (CDU) 2021 года. На плакате на фоне природного пейзажа представлен портрет кандидата партии. Информативная часть плаката состоит из четырёх элементов: в верхнем правом углу указано наименование партии (CDU), к которой принадлежит кандидат, в нижнем правом углу - дата проведения выборов (Am 14. März), сопровождаемая изображением элемента бюллетеня (кру́гом с крестиком), в нижнем левом углу плаката - ссылка на сайт кандидата партии (stefan-leukel. de), в верхнем левом углу указаны данные о кандидате имя и фамилия, а также должность, на которую он претендует, и представляемый город:

Stefan Leukel

Ihr Bürgermeister für die

VG Hachenburg

В персуазивно-апеллятивную часть плаката входит лозунг "Gutes erhalten. Zukunft gestalten!", который расположен над персоналиями и выражен двумя инфинитивными конструкциями с императивной семантикой.

Примечательно, что исторически информативная часть была основной в структуре любого плаката, т.к. он служил первоначально средством передачи информации [6, с. 103]. С течением времени функциональная нагрузка плаката претерпела изменения, добавились такие функции как аттрактивная, эстетическая, апеллятивная (доминирующая для текста политического плаката).

Опираясь на структурно-семантическую организацию и универсальные прагматические установки текста политического плаката, можно выделить несколько их (под)-типов: (1) плакаты, содержащие только вербальный компонент; (2) плакаты, не содержащие вербальный компонент; (3) мультимодальные плакаты (содержащие и вербальный и невербальный компоненты). Все указанные (под)-типы плаката являются семиотически осложнёнными. Плакаты, в структуру которых входит только графический текст, являются таковыми, поскольку в них, несмотря на отсутствие иконического компонента, задействованы цветовой код (цветовое оформление фона плаката, текста) и графическая вариативность (разные конфигурации и размеры шрифта, расположение текста в пространстве плаката). В плакатах без вербальной части реализуются иконический и цветовой коды. В мультимодальных плакатах задействовано наибольшее 
количество кодов: вербальный, иконический, цветовой и графический. Несмотря на то, что в современной политической агитации в Германии, по нашим наблюдениям, присутствуют все три названных подтипа плаката, лидирующую позицию среди них занимают мультимодальные политические плакаты, которые представляют наибольший интерес в аспекте изучения прагматического потенциала лингвокреативных текстовых элементов.

C позиций изучения лингвокреативности представляется интересным проследить, в какой из частей политического плаката (информативной или персуазивно-апеллятивной) она зарождается. Анализ продемонстрировал, что плакаты в данном случае также можно разделить на три группы:

1. плакаты, в которых лингвокреативность проявляется в информативной части. Такие плакаты составляют 2 \% от общего числа проанализированных плакатов. В данную группу входят плакаты, в текстах которых обыгрываются либо имена кандидатов партий, либо названия города, округа, в котором проходят выборы.

В качестве примера приведём предвыборный плакат партии ХДС (CDU) 2020 года в Бонне, в тексте которого лингвокреативность строится за счёт созвучия фамилии кандидата и названия города. На плакате представлена фотография кандидата партии Николь Бонни, сопровождаемая указанием её имени, города и поста, на который она баллотируется:

Nicole Bonnie für Bonn

Kandidatin Bezirksbürgermeisterin

Имя политика оформлено розовым цветом, перекликающимся с цветом жакета на фотографии, и шрифтом, имитирующим рукописный. Оно напечатано диагонально к части предложения Bonnie für Bonn. Через созвучие фамилии и названия города имплицитно подчёркивается, что это лучший кандидат на пост.

Географическое название обыгрывается на предвыборном плакате партии Зелёных (Die Grünen) 2016 года в Берлине. На плакате адресат видит фотографию кандидата партии Дженни Нойберт и подпись:

WEDDING? JA, ICH WILL!

Веддинг - это район Берлина. Лингвокреативность здесь проявляется благодаря тому, что название района города омонимично английскому слову Wedding («венчание», «бракосочетание»). Ответ "Ja, ich will!" также вызывает ассоциации с бракосочетанием, поскольку таким образом традиционно отвечают на вопрос “Willst du mich heiraten?"

Важно отметить, что в современных политических плакатах очень редко информативная часть не отягоще- на персуазивно-апеллятивной частью. В подобных случаях можно говорить об имплицитной персуазивности. В указанном примере в прямой речи кандидата (метонимически) инсценируется её согласие служить жителям района. Информативность за счёт лингвокреативности комплементарно соединяется с персуазивной стратегией, благодаря чему происходит углубление, обогащение смысла всего текста плаката.

2. Плакаты, в которых лингвокреативность заключена в персуазивно-апеллятивной части. Такие плакаты составляют 89,5 \% от общего числа проанализированных плакатов. Приведём примеры.

На плакате Левой партии (die Linke) 2021 года в персуазивно-апеллятивную часть входит лозунг, расположенный на красно-бордовом фоне, в котором за счёт созвучия слов в инфинитивной апеллятивной конструкции создаётся рифма:

Frieden

schaffen

ohne Waffen.

Bomben raus!

Информативная часть плаката не содержит лингвокреативных включений, в неё входит только название партии.

Ещё одним похожим примером может послужить плакат партии АдГ (AfD) 2017 года, посвящённый миграционной политике Германии. Персуазивно-апеллятивная часть данного плаката состоит из двух элементов: лозунга и изображения. На фотографии мы видим двух девушек в бикини на пляже, запечатлённых со спины, и подпись:

"BURKAS?"

WIR STEH'N AUF BIKINIS.

Указывая на отказ от бурки (легко узнаваемого элемента исламской культуры), партия демонстрирует своё отношение к притоку иммигрантов в страну. В информативную часть данного плаката входит название партии и её символ - красная стрелка.

3. Смешанная группа плакатов. Такие плакаты составляют 8,5 \% от общего числа проанализированных плакатов. В данную группу входят:

- плакаты, в текстах которых имена кандидатов от партии обыгрываются, и при этом они входят в лозунг.

Например, на плакате партии СДПг (SPD) 2017 года фотография кандидата партии Александра Хорламуса сопровождается лозунгом "Alex ISTMÖGLICH", т.е. обыгрывается имя политика (Alex - сокращённая форма имени Alexander). Эта же сокращённая форма имени дублируется во втором лозунге: 


\section{ES IST SO EINFACH:}

Erststimme Alex

Zweitstimme SPD

- плакаты, в которых информативная и персуазивноапеллятивная части соединены.

В качестве примера можно привести плакат партии ХДС (CDU) 2012 года в Северной Норд-Вестфалии, в апеллятивном тексте [ср.: 8] которого одновременно содержится призыв голосовать, указание имени кандидата партии и сокращённого имени федеральной земли, где проходят выборы (первые буквы слов лозунга выделены жёлтым цветом):

NORBERT

RÖTTGEN

WÄHLEN

За счёт продуманного вертикального расположения лексико-семантических элементов (напечатанных заглавными буквами) и цветового выделения авторы текста в содержательно максимально концентрированной вербальной части плаката креативно и аттрактивно призывают адресата голосовать за кандидата от партии.

- плакаты, в которых проявления лингвокреативности есть и в информативной, и в персуазивно-апеллятивной композиционно-смысловых частях текста, однако, при этом их элементы не связаны между собой так тесно, как в первой группе плакатов.

Рассмотрим в данной связи плакат партии СвДП (FDP) 2011 года. Информативная часть плаката состоит из названия партии и города (FDP Hamburg), в котором проходят выборы, и имени кандидата (Katja Suding). Имя кандидата расположено в нижней части плаката в центре, часть имени -ја выделена жирным шрифтом и курсивом, тем самым омонимически соответствуя утвердительной частице. Подобным образом потенциальному избирателю предлагается сказать "да" кандидату и партии, т.е. проголосовать за них на выборах. Этот креативно имплицированный в морфологический состав слова косвенный призыв дополняется лексически и синтаксически симметрично построенным двусоставным лозунгом в персуазивно-апеллятивной части плаката:

Positiv denken.

Positiv handeln.

Приведённые примеры показывают, что прагматическая сила политического плаката возникает не в последнюю очередь в результате взаимодействия его вербально-визуальных элементов. Особенности этого взаимодействия определяются такой текстовой категорией как связность, т.е. наличием содержательной и формальной связи между частями текста (в данном случае между вербальной и иконической составляю- щими плаката). Связность реализуется на трёх уровнях: содержательном, содержательно-языковом и содержательно-композиционном [1; 2]. Опираясь на положения Е.Е. Анисимовой о видах связи, рассмотрим на конкретных примерах, как различные типы связности на данных уровнях структуры немецкого политического плаката демонстрируют лингвокреативность создателей текста и обеспечивают композиционно-смысловую цельность этого типа текста.

На содержательном уровне связность между вербальной и иконической составляющими плаката представлена двумя типами:

1. Прямая денотативная связь - знаки обеих семиотических систем определяют одни и те же объекты. Лингвокреативную нагрузку при данном типе связности элементов несут языковые средства, а изображение выполняет информационную функцию, оно полностью или частично дублирует прагмасемантику, выраженную на плакате вербально. В качестве примера приведём политический плакат партии СвДП (FDP) 2015 года. Иконическая составляющая данного плаката, представленная фотографией кандидата партии Ленке Штайнер, служит иллюстрацией к подписи. В вербальной части текста плаката приводятся персоналии обозначаемого лица и даётся его характеристика:

Lencke Steiner

Wirtschafts- und

Wirschaffendas-

Expertin!

Лингвокреативность здесь реализуется полностью за счёт языка: посредством анафоры (Wirtschafts- und Wirschaffendas), где особо выделяется часть слов wir (можно интерпретировать как личное местоимение), благодаря чему стирается граница между адресантом (политической партией и её представителем) и адресатом (избирателями). Окказиональный неологизм Wirschaffendas-Expertin, образованный с помощью парономазии, представляет собой аллюзивную ссылку на известные гражданам Германии слова канцлера Ангелы Меркель. Это позволяет авторам плаката, с одной стороны, продемонстрировать свою осведомлённость о политической ситуации и действиях оппонентов, а с другой подчеркнуть социально-политическую компетентность своего кандидата.

2. Опосредованная денотативная связь - знаки семиотических систем определяют различные объекты, связанные между собой (общей) темой или посредством ассоциаций. Например, на плакате партии СДПГ (SPD) 2015 года на красном фоне (партийный цвет) мы видим фотографию, на которой запечатлены три объёмных живота в профиль. Изображение сопровождается лозунгом "Oranienburg wächst". Хотя картинка непосредственно и 
не связана с лозунгом (речь идёт об увеличении численности населения города), адресат может распознать метафорическую ассоциацию с увеличением (рост живота и рост города). Креативность здесь проявляется именно благодаря ассоциативно-образному взаимодействию семантики знаков разных систем.

На содержательно-языковом уровне связность между вербальной и иконической составляющими плаката представлена двумя типами:

1. Эксплицитно выраженная связность, которая предполагает три вида связи между компонентами плаката: структурную, идентифицирующую, дейктическую.

(A) В случае структурной связи между компонентами плаката иконическая и вербальная составляющие тесно сопряжены: иконический знак встроен в вербальньную часть плаката, замещая определённый вербальный знак, что позволяет создать запоминающийся лозунг с высоким воздействующим потенциалом и сократить пространственный объём текста. Так, например, на плакате ХДС (CDU) 2017 года лозунг, в тексте которого обыгрывается фамилия кандидатки от партии, выглядит следующим образом:

\section{Christina}

Schwarzer

\section{Schwarzfahren \\ Schwarzer wählen}

Используемые эмотиконы (эмотикон с насупленными бровями и опущенной улыбкой для выражения недовольства и эмотикон, изображающий палец, поднятый вверх в знак одобрения) рождают риторическую фигуру антитезы оценочного характера, персуазивно нацеливающую адресата на выбор представительницы партии.

(Б) Идентифицирующая связь между вербальной и иконической составляющими политического плаката проявляется в том, что иконическая составляющая изображает адресанта (представителя партии) или адресата сообщения (избирателей). К языковым проявлениям такой связи относят обычно использование личных и притяжательных местоимений 1 и 2 лица. Например, на плакате партии Зелёных (Die Grünen) 2017 года с лозунгом "Ich lass euch nicht im Regen stehen" личное местоимение ich указывает на связь вербального компонента с изображением - фотографией кандидата партии Зелёных Оливера Биттмана, который держит в руке зонт. Лингвокреативность в данном случае проявляется благодаря взаимодействию изображения и текста: автор плаката обыгрывает (а) выражение im Regen stehen lassen, имеющее метафорическое значение «бросить в беде, оставить в трудной ситуации», и (б) его визуализацию с помощью картинки зонта и дождя.
(B) Дейктическая связь мультимедиальных частей плаката выражается в том, что в вербальной составляющей текста содержится лексико-семантическая проекция на его иконическую часть. В качестве примера можно привести плакат партии Зелёных (Die Grünen) 2010 года с лозунгом "Banken, die wir fördern. Mehr Geld in Bildung statt in Banken" и изображением школьной парты старого образца, соединённой со скамьёй. Лингвокреативность данного плаката создаётся благодаря словам-омонимам (die Bank - нем. банк, скамья), различающимся только формой множественного числа. Парта здесь - метонимический зрительный образ устаревшей школы, она символизирует необходимость изменений школьного образования, которые невозможны без финансовых вложений.

2. Имплицитно выраженная связность предполагает, что композиционно-смысловая соотнесенность вербальной и иконической составляющих поликодового текста опосредована и неявна. При таком типе связности в тексте должны быть маркеры, указывающие на наличие в плакате некой (пред-)информации, как, например, на плакате партии АдГ (AfD) 2017 года на тему миграционной политики Германии. На плакате избиратель видит фотографию лежащей беременной девушки-немки, сопровождаемую лозунгом в вопросно-ответной форме:

"Neue Deutsche?"

Machen wir selber.

Прединформация выражена в вербальной части плаката помещённой в кавычки цитатой, которая представляет собой прямую ссылку на лозунги оппозиционных АдГ партий, призывающих к гражданской ассимиляции мигрантов в ФРГ. Придание этой цитате синтаксической формы вопроса-переспроса ("Neue Deutsche?") помогает авторам плаката расширить когнитивно-эмоциональное пространство текста в агрессивно-полемическом прагматическом ключе.

На содержательно-композиционном уровне текста речь идёт о семантических отношениях между составляющими плаката, участвующих в создании смыслового текстового целого. Подобные отношения обнаруживаются в визуально-пространственном расположении вербальной и иконической составляющих политического плаката, дополненном семантической соотнесённостью их отдельных элементов. Например, они могут проявляться в связи иконической составляющей плаката с буквой, словом/словосочетанием, предложением или со всем текстом. В качестве иллюстрации можно привести плакат партии Зелёных (Die Grünen) 2014 года. На плакате изображено кукурузное поле, на котором стоит знак генно-модифицированных продуктов. Лозунг гласит: “GENug!". Благодаря выделению части слова заглавными буквами между вербальной составляющей плаката и изображением 
устанавливается однозначное семантическое соответствие, что позволяет эффективнее воздействовать на адресата.

Таким образом, взаимодействие вербальной и визуальной составляющих политического плаката как проявление лингвокреативности его создателей носит разнообразный характер. Несмотря на различие типов связи между их компонентами, можно - на основе наличия целого ряда повторяющихся закономерностей в структурировании текстов политического плаката - выделить два типа плакатов:

1. Политические плакаты, в которых лингвокреативность проявляется, в первую очередь, за счёт используемых в тексте оригинальных языковых средств. Невербальная составляющая в таких плакатах имеет «комплементарную», то есть дополнительную, функцию аттракции, или привлечения внимания адресата к информации, вербально выраженной в тексте.

2. Плакаты, в которых креативность в полной мере раскрывается только при целостном восприятии коммуникативно и прагматически «равнозначных» вербального и невербального компонентов, взаимодополняющих друг друга.

Исходя из вышеизложенного можно заключить, что лингвокреативность в тексте политического плаката может иметь характер либо «абсолютной» лингвокреативности, в создании которой задействованы только языковые единицы, либо синкретической лингвокреативности, которая возникает благодаря взаимодействию вербальных и невербальных элементов.

Анализ проявлений лингвокреативности в разных композиционно-смысловых частях современного немецкого политического плаката (информативной и персуазивно-апеллятивной) позволяет сделать вывод о том, что лингвокреативные средства используются преимущественно в его персуазивно-апеллятивной части, что объясняется функцией агитационно-пропагандистского воздействия, присущей данному типу текста в качестве главного прототипического коммуникативно-прагматического признака.

\section{ЛИТЕРАТУРА}

1. Анисимова Е.Е. Паралингвистика и текст (к проблеме креолизованных и гибридных текстов) // Вопросы языкознания. 1992. № 1. С. 71-78. URL: http://issuesinlinguistics.ru/pubfiles/1992-1_71-78.pdf (дата обращения: 25.03.2021).

2. Анисимова Е.Е. Лингвистика текста и межкультурная коммуникация (на материале креолизованных текстов). М.: Академия, 2003.128 с.

3. Бернацкая А.А. Подпись как тип текста // Проблемы лингвистического анализа текста и коммуникации. Иркутск: Педагогический институт, 1987. С. 8-128.

4. Бернацкая А.А. К проблеме “креолизации" текста: история и современное состояние // Речевое общение: специализированный вестник. 2000. Вып. 3 (11). C. 104-110.

5. Большакова Л.С. О содержании понятия «поликодовый текст» // Вестник СамГУ. 2008. № 63. С. 19-24. URL: https://cyberleninka.ru/article/n/o-soderzhaniiponyatiya-polikodovyy-tekst-1 (дата обращения: 15.02.2021).

6. Гончарова Е.А. Текстовые и дискурсные характеристики современного немецкого политического плаката // Известия смоленского государственного университета. 2021. № 1 (53). C. 102-117. URL: https://www.elibrary.ru/item.asp?id=44949919 (дата обращения: 22.03.2021).

7. Добросклонская Т.Г. Методы анализа видео-вербальных текстов // Медиалингвистика. 2016. № 2 (12). C. 13-25. URL: https://www.elibrary.ru/item. asp?id=26099878 (дата обращения: 31.03.2021).

8. Комлева Е.В. Апеллятивность и текст: (на материале современного немецкого языка). СПБ: Реноме, 2014. 354 с.

9. Михеев А.В. 0 некоторых типах взаимодействия изображения и текста // Типы коммуникации и содержательный аспект языка: сб. науч. тр. М.: АН ссСР, Институт языкознания, 1987. С. 191-199.

10. Некрасова Е.Д. К вопросу о восприятии полимодальных текстов // Вестник Томского государственного университета. 2014. № 378. С. 45-48. URL: http://vital.lib.tsu.ru/vital/access/manager/Repository/vtls:000470866 (дата обращения: 30.03.2021).

11. Пойманова 0.В. Семантическое пространство видеовербального текста: автореф. дис. ... канд. филол. наук: 10.02.19. М., 1997. 24 с.

12. Протченко А.В. Типологические и функционально-стилистические характеристики англоязычного путеводителя: автореферат дис. ... канд. филол. наук: 10.02.04. Самара, 2006. $19 \mathrm{c}$.

13. Сонин, А.Г. Экспериментальное исследование поликодовых текстов: основные направления // Вопросы языкознания. М., 2005. №6. С. 115-123. URL: https://vja.ruslang.ru/ru/archive/2005-6/115-123 (дата обращения: 05.04.2021).

14. Сонин А.Г. Моделирование механизмов понимания поликодовых текстов: автореф. дис. . . . д-ра филол. наук: 10.02.19. М., 2006. 42 с.

15. Сорокин Ю.А., Тарасов Е.Ф. Креолизованные тексты и их коммуникативная функция // Оптимизация речевого воздействия: коллективная монография. M., 1990. C. 180-186.

( Филатова Алёна Григорьевна (alyonafilatowa@gmail.com).

Журнал «Современная наука: актуальные проблемы теории и практики» 